\title{
Natural plant stems modelling in a three-point bending test
}

\author{
Bartosz Kawecki ${ }^{1, *}$, Jerzy Podgórski ${ }^{1}$, and Aleksandra Głowacka ${ }^{2}$ \\ ${ }^{1}$ Faculty of Civil Engineering and Architecture, Lublin University of Technology, Nadbystrzycka 40, 20-618 Lublin, Poland \\ ${ }^{2}$ Faculty of Agrobioengineering, University of Life Sciences in Lublin, Akademicka 13, 20-950 Lublin, Poland
}

\begin{abstract}
The paper presents an approach to natural plant stems numerical modelling in a three-point bending test. Introduced subject was connected with elaborating more efficient systems for harvesting energetic plants. There were modelled, and laboratory tested two types of stems - sida hermaphrodita and miscanthus giganteus. Course of proceedings for obtaining natural cross-sectional dimensions with graphical data processing was described in detail. Basing on dozens of stems slices from random parts of plants, three different cross-section approximations were proposed and computationally implemented - a circular pipe, an elliptical pipe (symmetrical cross-section) and a sine-cosine series pipe (asymmetrical crosssection). Analytical formulas for calculating a cross-sectional area and moments of inertia for each approximation were given. Basic material parameters as an elastic modulus and yielding stress was obtained from simply supported beam theory and laboratory force - the deflexion relation. FEM models were created in Simulia Abaqus software using C3D20R elements. Preliminary approach to modelling damage with perfect plasticity was done basing on several samples bended to failure in laboratory tests. Conclusions for future work with numerical modelling natural plant stems were drawn.
\end{abstract}

\section{Introduction}

\subsection{Subject description}

Methods for harvesting energetic plants and especially influence of different kind of factors on cutting process are still under development. Because numerical modelling is a recent method for predicting wide range of processes, it was proposed to be used in modelling cutting of stems. To obtain suitable models corresponding to reality it was necessary to determine appropriate assumptions for computational modelling. In the paper there were presented methods for approximating cross-sectional parameters and a first attempt to damage modelling through perfect plastic behaviour of the material. Presented subject is a preliminary work and modelling is still under development.

\subsection{Plants description}

Sida hermaphrodita and miscanthus giganteus are perennial plants belonging to the group of non-food renewable energy sources $[1,2,3]$.

Sida hermaphrodita is a native North America perennial crop with strongly developed root system that grows intensively from the second year of vegetation. It reproduces both generatively from seeds and vegetatively from root cuttings obtained from the carp division. The height of several year-old plants is $250-300 \mathrm{~cm}$ and the diameter of the stem ranges from 5 to $40 \mathrm{~mm}$ [4].

Miscanthus giganteus is a sterile hybrid plant farmed in the 1980s in Denmark. It is characterised by rapid growth, high productivity of above-ground biomass, and relatively low sensitivity to low temperatures, especially in the first year of vegetation. Miscanthus Giganteus does not produce seeds and is propagated vegetatively, most often through rhizomes cuttings obtained from the division of root carps of mother plants [5].

\section{Cross-sectional parameters}

Basic characteristics that allows to obtain mechanical properties of any kind of examined material are crosssectional area and moments of inertia. Every mechanical property highly depends on these values [6]. Because of that, determining these parameters seemed to be one of the most significant problems to solve. Dimensions such as wall thickness and outer diameter of each kind of stems varied on the length and cross-sections took different kind of shapes.

a)

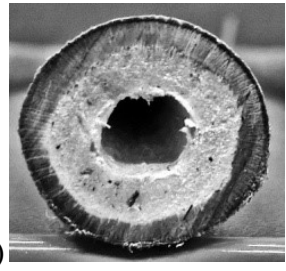

b)

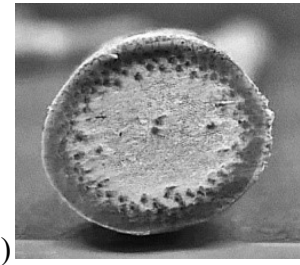

Fig. 1. Original natural cross-sections: a) sida hermaphrodita, b) miscanthus giganteus.

There was noticed that white core in both kind of stems had low density and might be easily removed from the stem. Original natural cross-sections were presented in Fig. 1. Comparing fibres to the core, they were rigid and strong. Because of that, there was assumed that a load-bearing part of the stem would be only fibres and

${ }^{*}$ Corresponding author: b.kawecki@pollub.pl 
white core may be neglected without influence on general plant stiffness.

\subsection{Graphical method for determining natural cross-sectional dimensions}

There were prepared 40 cross-section slices for each kind of plants from random parts and harvesting time of stems. Each slice was drilled from the easily removable core and coloured with black ink. Then it was photographed in high resolution next to millimetre paper and in every picture only black colour was isolated. Next, using Autodesk AutoCAD software [7] every taken picture was scaled with precision of $0.01 \mathrm{~mm}$ to real dimensions. These processes allowed to achieve detailed contour of each probe. Examples of probes were presented in Fig. 2. and their vectorial contours in Fig. 3.

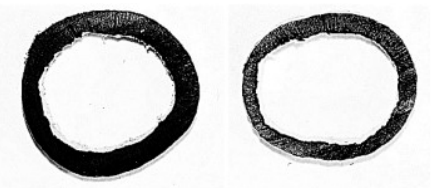

a)

Fig. 2. Black coloured cross-section pictures

a) sida hermaphrodita, b) miscanthus giganteus.
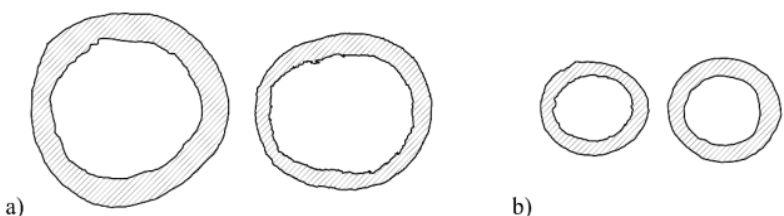

b)

Fig. 3. Scaled cross-section vectorial contours:

a) sida hermaphrodita, b) miscanthus giganteus.

In the next step there was carried out dimensions study of each probe. In every of them geometric centre was determined and external and internal diameter in 45 degrees step was measured. Explanation was presented in Fig. 4.
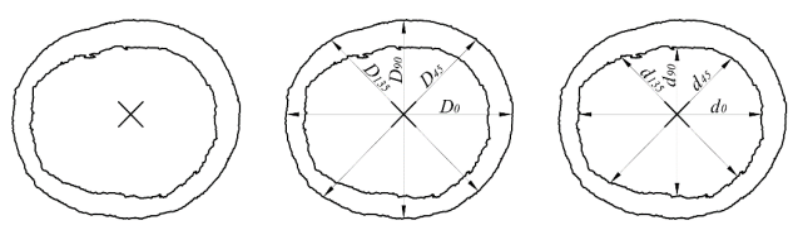

Fig. 4. Example of sample cross-sectional dimensions study.

Example values of dimensions and natural crosssectional properties study were given consecutively in Table 1, Table 2, and Table 3.

Table 1. Sida hermaphrodita cross-sectional dimensions.
Internal diameter $[\mathrm{mm}]$

\begin{tabular}{|c|c|c|c|c|c|c|c|c|}
\cline { 2 - 9 } & $D_{0}$ & $D_{45}$ & $D_{90}$ & $D_{135}$ & $d_{0}$ & $d_{45}$ & $d_{90}$ & $d_{135}$ \\
\hline 1 & 15.29 & 14.61 & 14.30 & 14.43 & 10.67 & 10.14 & 9.58 & 9.69 \\
\hline 2 & 14.55 & 14.36 & 13.94 & 14.23 & 11.26 & 11.08 & 10.72 & 11.01 \\
\hline 3 & 15.70 & 15.04 & 14.34 & 14.83 & 10.26 & 9.32 & 9.47 & 10.00 \\
\hline 4 & 14.90 & 14.61 & 14.32 & 14.68 & 10.58 & 10.20 & 9.67 & 10.03 \\
\hline 5 & 14.57 & 14.18 & 13.26 & 13.89 & 9.87 & 9.23 & 9.13 & 10.26 \\
\hline 6 & 14.67 & 14.00 & 12.95 & 13.62 & 11.42 & 11.22 & 10.25 & 10.76 \\
\hline 7 & 13.23 & 12.52 & 12.02 & 12.76 & 10.65 & 10.14 & 9.45 & 10.02 \\
\hline 8 & 14.32 & 13.49 & 13.26 & 13.86 & 8.61 & 8.23 & 8.41 & 8.76 \\
\hline 9 & 13.22 & 12.66 & 11.29 & 12.18 & 10.73 & 10.07 & 8.47 & 9.66 \\
\hline 10 & 13.78 & 13.51 & 13.34 & 13.62 & 8.75 & 7.81 & 7.83 & 8.00 \\
\hline
\end{tabular}

Table 2. Miscanthus giganteus cross-sectional dimensions.

\begin{tabular}{|c|c|c|c|c|c|c|c|c|}
\hline \multirow{2}{*}{ 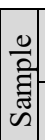 } & \multicolumn{4}{|c|}{$\begin{array}{c}\text { External diameter } \\
{[\mathrm{mm}]}\end{array}$} & \multicolumn{4}{|c|}{$\begin{array}{c}\text { Internal diameter } \\
{[\mathrm{mm}]}\end{array}$} \\
\hline & $D_{0}$ & $D_{45}$ & $D_{90}$ & $D_{135}$ & $D_{0}$ & $D_{45}$ & $D_{90}$ & $D_{135}$ \\
\hline 1 & 8.69 & & & & & 45 & 18 & \\
\hline 2 & 9.67 & & & & & & & \\
\hline 3 & 8.12 & 7.29 & & 35 & 6.03 & 5.36 & .83 & 19 \\
\hline 4 & \begin{tabular}{|l}
7.49 \\
\end{tabular} & 6.97 & 7.06 & .23 & 5.82 & 5.15 & .90 & .25 \\
\hline 5 & 8.70 & 7.87 & 7.59 & 8.16 & 6.01 & 5.77 & 5.27 & 5.5 \\
\hline 6 & 8.44 & 8.13 & 7.92 & 8.19 & 5.77 & 5.57 & 5.55 & 5.6 \\
\hline & 7.80 & .09 & & 7.29 & .85 & 5.27 & 4.82 & 5.12 \\
\hline 8 & 8.02 & 7.50 & 7.10 & 7.42 & 5.80 & 5.34 & 5.41 & 5.61 \\
\hline 9 & 7.62 & 6.88 & 6.46 & 6.76 & 5.49 & 4.81 & 4.51 & 4.99 \\
\hline & 8.49 & 7.82 & 7.56 & 7.92 & 5.71 & 5.49 & 5.03 & 5.4 \\
\hline
\end{tabular}

Table 3. Stems natural cross-sectional properties.

\begin{tabular}{|c|c|c|c|c|c|c|}
\hline \multirow{2}{*}{ 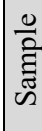 } & \multicolumn{3}{|c|}{ Sida hermaphrodita } & \multicolumn{3}{|c|}{ Miscanthus giganteus } \\
\hline & $\begin{array}{c}A_{N} \\
{\left[\mathrm{~mm}^{2}\right]}\end{array}$ & $\begin{array}{c}J_{x N} \\
{\left[\mathrm{~mm}^{4}\right]}\end{array}$ & $\begin{array}{c}J_{y N} \\
{\left[\mathrm{~mm}^{4}\right]}\end{array}$ & $\begin{array}{c}A_{N} \\
{\left[\mathrm{~mm}^{2}\right]}\end{array}$ & $\begin{array}{c}J_{x N} \\
{\left[\mathrm{~mm}^{4}\right]}\end{array}$ & $\begin{array}{c}J_{y N} \\
{\left[\mathrm{~mm}^{4}\right]}\end{array}$ \\
\hline 1 & 87.4 & 1664.2 & 1782.5 & 26.2 & 137.7 & 179.0 \\
\hline 2 & 66.0 & 1277.7 & 1394.5 & 27.6 & 163.8 & 246.8 \\
\hline 3 & 99.8 & 1836.1 & 2173.0 & 21.0 & 92.8 & 128.3 \\
\hline 4 & 84.9 & 1662.8 & 1713.2 & 18.6 & 88.3 & 96.5 \\
\hline 5 & 80.0 & 1318.7 & 1570.9 & 25.6 & 135.3 & 179.6 \\
\hline 6 & 54.2 & 948.5 & 1185.0 & 27.4 & 157.5 & 183.1 \\
\hline 7 & 46.7 & 734.3 & \begin{tabular}{|l|}
790.1 \\
\end{tabular} & 19.9 & 88.5 & 112.2 \\
\hline 8 & 89.4 & 1338.3 & 1577.3 & 20.2 & 95.6 & 125.4 \\
\hline 9 & 43.7 & 603.9 & 749.3 & 18.7 & 72.1 & 99.3 \\
\hline 10 & 91.1 & 1390.6 & 1437.2 & 26.7 & 140.1 & 170.9 \\
\hline
\end{tabular}

\subsection{Circular pipe approximation}

First proposed method for approximating natural irregular cross-section was a circular pipe approximation based on averaged external and internal diameter. Pattern was presented in Fig. 5. Formulas for calculating pipe crosssectional area and moments of inertia were given below. 

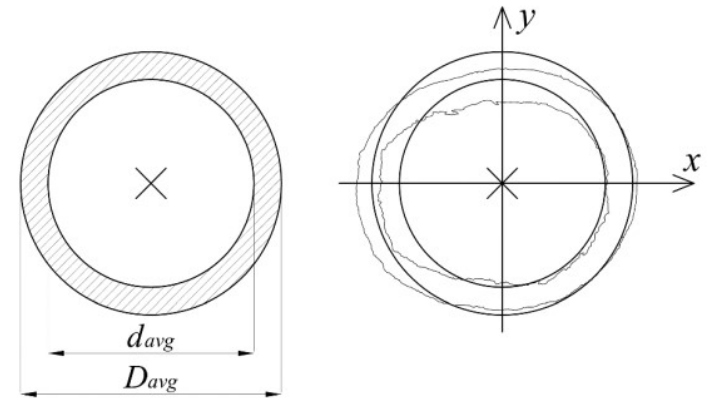

Fig. 5. Circular pipe cross-section approximation.

$$
\begin{gathered}
D_{a v g}=\frac{D_{0}+D_{45}+D_{90}+D_{135}}{4} \\
d_{a v g}=\frac{d_{0}+d_{45}+d_{90}+d_{135}}{4} \\
A_{C}=\frac{\pi}{4}\left(D_{a v g}{ }^{2}-d_{a v g}^{2}\right) \\
J_{x C}=J_{y C}=\frac{\pi}{64}\left(D_{a v g}^{4}-d_{\text {avg }}^{4}\right)
\end{gathered}
$$

Average approximation accuracy error [8] of area and moments of inertia were consecutively on the level of $2.0 \%$ and $5.1 \%$ for sida hermaphrodita or $1.4 \%$ and $13.6 \%$ for miscanthus giganteus stems.

\subsection{Elliptical pipe approximation}

Second proposed method for approximating natural irregular cross-section was an elliptical pipe approximation based on maximum diameter and diameter measured perpendicularly to the previous one. Pattern was presented in Fig. 6. Formulas for calculating pipe crosssectional area and moments of inertia were given below.
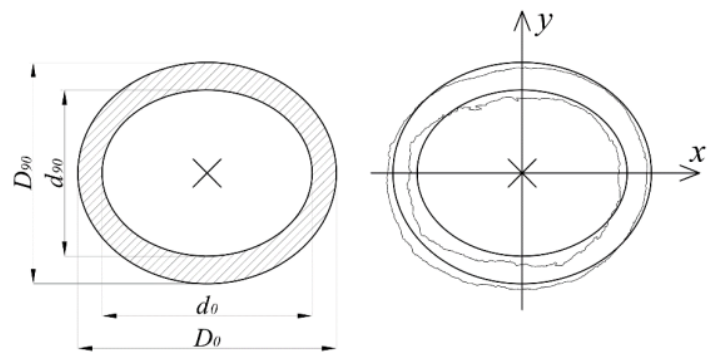

Fig. 6. Elliptical pipe cross-section approximation.

$$
\begin{gathered}
A_{E}=\frac{\pi}{4}\left(D_{0} \cdot D_{90}-d_{0} \cdot d_{90}\right) \\
J_{x E}=\frac{\pi}{64}\left(D_{0} \cdot D_{90}{ }^{3}-d_{0} \cdot d_{90}{ }^{3}\right) \\
J_{y E}=\frac{\pi}{64}\left(D_{90} \cdot D_{0}{ }^{3}-d_{90} \cdot d_{0}{ }^{3}\right)
\end{gathered}
$$

Average approximation accuracy error [8] of area and moments of inertia were consecutively on the level of $3.2 \%$ and $3.7 \%$ for sida hermaphrodita or $3.2 \%$ and $3.4 \%$ for miscanthus giganteus stems.

\subsection{Sine-cosine series pipe approximation}

Third proposed method for approximating natural irregular cross-section was a sine-cosine series pipe approximation based on four diameters measured in 45 degree step. Pattern was presented in Fig. 7. Algorithm calculating both area and moments of inertia was implemented in PTC Mathcad software.
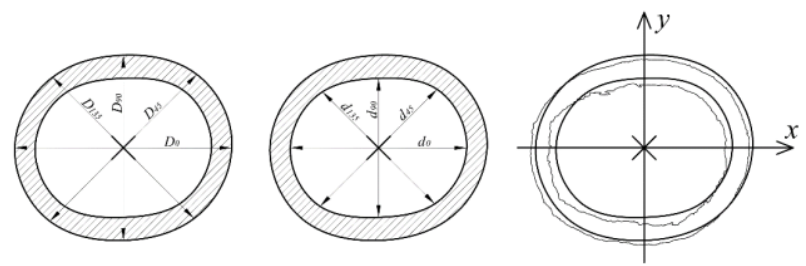

Fig. 7. Sine-cosine series pipe cross-section approximation.

$$
\begin{gathered}
A_{S}=\int_{0}^{\pi}\left[R_{z}(\alpha, \varphi)^{2}-R_{w}(\alpha, \varphi)^{2}\right] d \varphi \\
J_{x S}=\frac{1}{2} \int_{0}^{\pi}\left[R_{z}(\alpha, \varphi)^{4}-R_{w}(\alpha, \varphi)^{4}\right] \cdot \sin ^{2}(\varphi) d \varphi \\
J_{y S}=\frac{1}{2} \int_{0}^{\pi}\left[R_{z}(\alpha, \varphi)^{4}-R_{w}(\alpha, \varphi)^{4}\right] \cdot \cos ^{2}(\varphi) d \varphi
\end{gathered}
$$

where

$$
\begin{gathered}
R_{z}(\alpha, \varphi)=\alpha_{z 0}+\alpha_{z 1} \sin (2 \varphi)+\alpha_{z 2} \cos (2 \varphi)+\alpha_{z 3} \cos (4 \varphi) \\
R_{w}(\alpha, \varphi)=\alpha_{w 0}+\alpha_{w 1} \sin (2 \varphi)+\alpha_{w 2} \cos (2 \varphi)+\alpha_{w 3} \cos (4 \varphi) \\
\alpha_{z 0}=\frac{1}{8}\left(D_{0}+D_{45}+D_{90}+D_{135}\right) \\
\alpha_{z 1}=\frac{1}{4}\left(D_{45}-D_{135}\right) \\
\alpha_{z 2}=\frac{1}{4}\left(D_{0}-D_{90}\right) \\
\alpha_{z 3}=\frac{1}{8}\left(D_{0}-D_{45}+D_{90}-D_{135}\right) \\
\alpha_{w 0}=\frac{1}{8}\left(d_{0}+d_{45}+d_{90}+d_{135}\right) \\
\alpha_{w 1}=\frac{1}{4}\left(d_{45}-d_{135}\right) \\
\alpha_{w 2}=\frac{1}{4}\left(d_{0}-d_{90}\right) \\
\alpha_{w 3}=\frac{1}{8}\left(d_{0}-d_{45}+d_{90}-d_{135}\right)
\end{gathered}
$$

Average approximation accuracy error [8] of area and moments of inertia were consecutively on the level of $2.0 \%$ and $2.6 \%$ for sida hermaphrodita or $1.5 \%$ and $1.8 \%$ for miscanthus giganteus stems.

\subsection{Approximations for the samples}

Example cross-sections approximations were done basing on information included in the previous chapter. Samples were presented in Figs. 8-11. Samples denotations used in further part of the paper were (S) for sida hermaphrodita and $(\mathrm{M})$ for miscanthus giganteus. Cross-section approximations denotations were consecutively I, II, and 
III for a circular pipe, an elliptical pipe, and a sine-cosine series pipe.

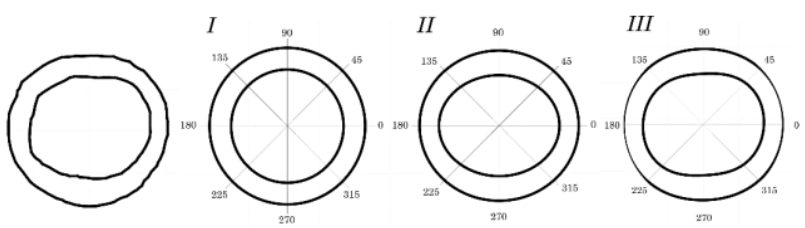

Fig. 8. S-1 sample cross-sections approximations.

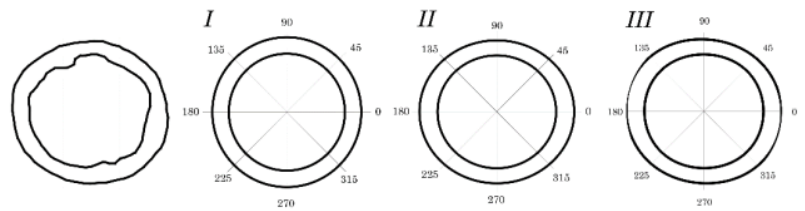

Fig. 9. S-2 sample cross-sections approximations.
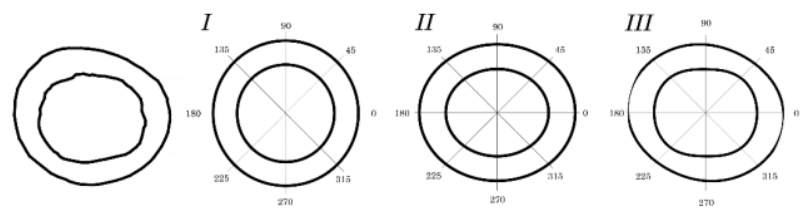

Fig. 10. M-1 sample cross-sections approximations.
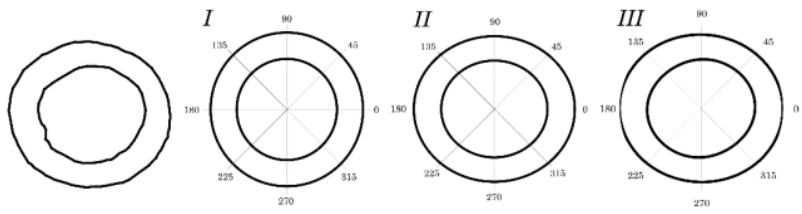

Fig. 11. M-2 sample cross-sections approximations.

Proposed graphical method for determining crosssectional parameters seemed to give relatively good results. There was stated that the most accurate, but also the most complicated method for approximating natural cross-section was a sine-cosine series pipe. Elliptical pipe did not cause a meaningful error and was a good and relatively simple solution, which could be easily used in a majority of FEM software. These two approximations were recommended to be applied in numerical modelling of the examined stems. The circular pipe approximation was recommended to be used only in case of fast and superficial calculations.

\section{Laboratory testing}

First attempt to material testing and modelling was based on isotropy assumption. Then, an elastic modulus might be calculated basing on transformed formula [9] for simply supported beam bending:

$$
E=\frac{L_{r}^{3}}{48 J} \cdot \frac{P}{x}
$$

Yielding stress was approximated according to simply supported beam theory, experimentally measured force and natural cross-sectional moment of inertia. Because samples height was small comparing to the length, shear stress was negligible and could be omitted [10]. Modified formula best fitted to laboratory test results was:

$$
\sigma_{p l}=\frac{P_{\max } L_{r} d_{90}}{8{ }_{x}}
$$

Graphical explanation of the above formula was presented in Fig. 12.

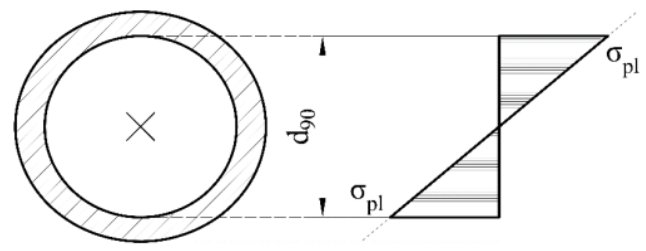

Fig. 12. Yield stress for samples.

Parameters obtained for tested samples and applied to FEM models were presented in Table 4.

Table 4. Parameters for tested samples.

\begin{tabular}{|c|c|c|c|c|c|c|}
\hline Sample & $\begin{array}{c}L_{r} \\
{[\mathrm{~mm}]}\end{array}$ & $\begin{array}{c}P / w \\
{[\mathrm{~N} / \mathrm{mm}]}\end{array}$ & $\begin{array}{c}J_{x} \\
{\left[\mathrm{~mm}^{4}\right]}\end{array}$ & $\begin{array}{c}d_{90} \\
{[\mathrm{~mm}]}\end{array}$ & $\begin{array}{c}E \\
{[\mathrm{GPa}]}\end{array}$ & $\begin{array}{c}f_{y} \\
{[\mathrm{MPa}]}\end{array}$ \\
\hline S-1 & 205 & 60.13 & 1720.7 & 9.64 & 5.93 & 27.99 \\
\hline S-2 & 205 & 30.96 & 659.5 & 9.22 & 8.43 & 37.62 \\
\hline M-1 & 101 & 37.86 & 57.3 & 3.81 & 14.19 & 63.12 \\
\hline M-2 & 101 & 69.56 & 92.1 & 4.49 & 16.22 & 67.55 \\
\hline
\end{tabular}

\section{FEM modelling}

There was created FEM model basing on the elliptical pipe approximation. Comparison of numerical model to laboratory test stand was presented in Fig. 13.

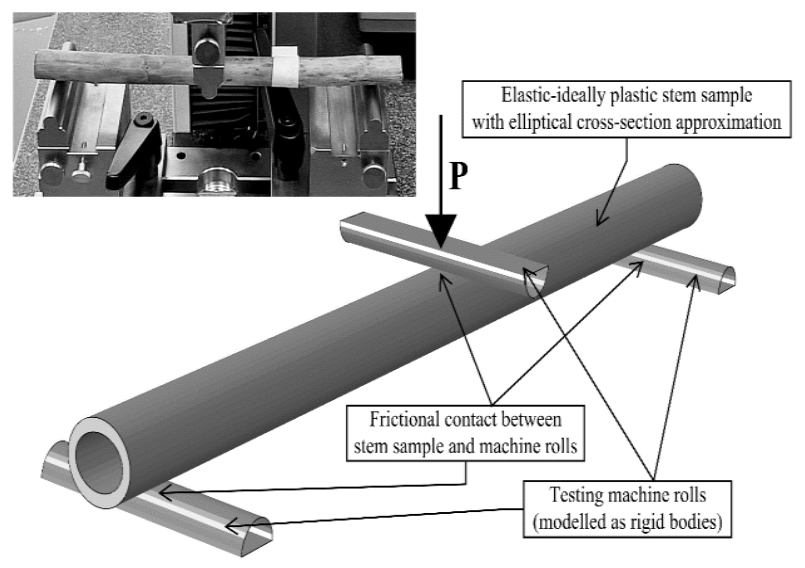

Fig. 13. General FEM model description with comparison to laboratory test stand.

There were precisely examined and modelled 4 samples using Simulia Abaqus software [11]. Numerical results in comparison to laboratory tests were presented in Fig. 14 for sida hermaphrodita and in Fig. 15 for miscanthus giganteus. 


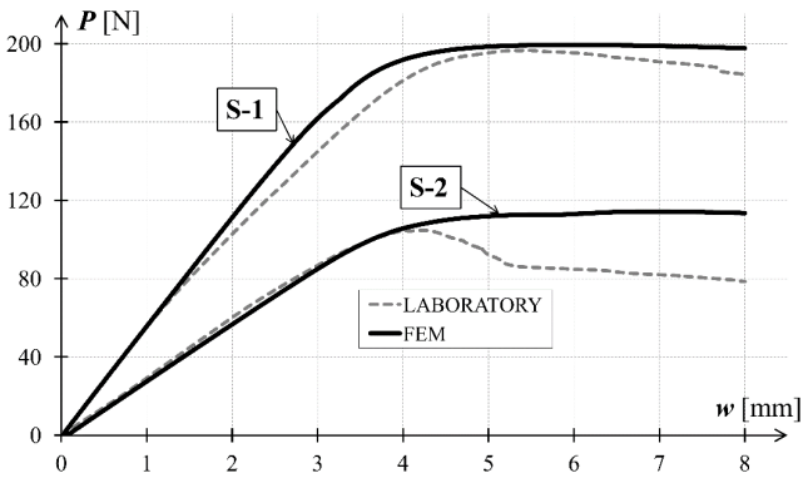

Fig. 14. Results for sida hermaphrodita samples.

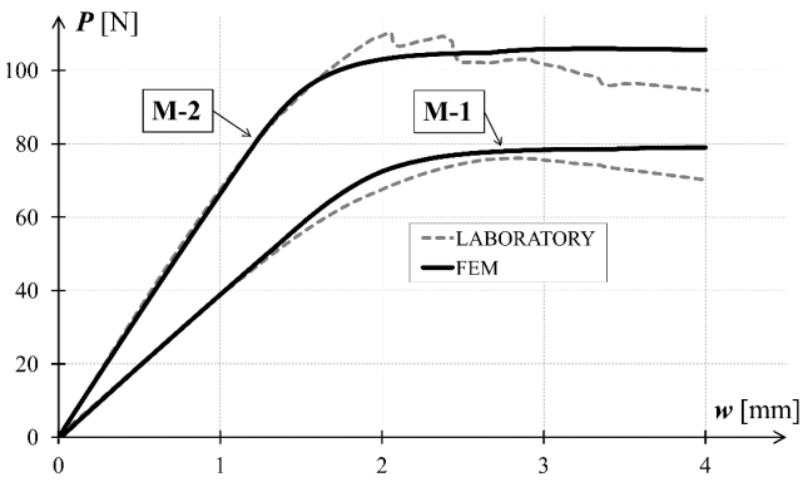

Fig. 15. Results for miscanthus giganteus samples.

Plasticised regions from numerical modelling at the end of the analysis of samples were presented in Fig. 16. There was also presented plasticity distribution in the middle cross-section.
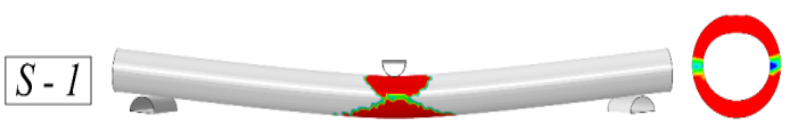

$S-2$
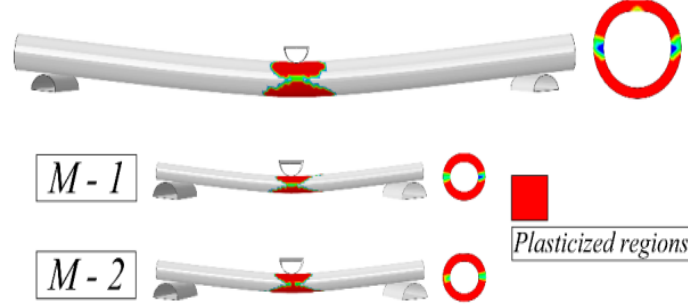
Plasticized regions

Fig. 16. Plasticized regions of the samples.

\section{Conclusions}

Simplified elastic-ideally plastic material model gave relatively good results, comparable to laboratory tests in the initial phase of damage processing. Presented FEM modelling might be useful in case of predicting strength of the stems without going into detailed damage analysis.

In a further phase of the test there was observed softening behaviour of the samples. Because developing the subject requires additional, complex laboratory tests, study would be undertaken in a future work.

It also might be advisable to take anisotropy into account. Tested material is a natural one and parameters may change in different directions. Elaborating nonstandard methods for detailed laboratory testing the material would another challenge to meet.

\section{References}

1. I. Lewandowski, J. Clifton-Brown, J. M. O. Scurlock, W. Huisman, Biomass Bioenergy 19, 209-227 (2000).

2. H. Borkowska, R. Molas, Biomass Bioenergy 36, 234-240 (2012)

3. H. Borkowska, R. Molas, Biomass Bioenergy 51, 145-153 (2013)

4. S. Szczukowski, J. Tworkowski, M. Stolarski, J. Kwiatkowski, M. Krzyżaniak, W. Lajszner, Ł. Graban, Perennial energy crops (Mulico Publishing Mouse, Warsaw, 2012, in Polish)

5. S. Cichorz, D. Gośka, R. Mańkowski, Industrial Crops and Products 116, 150-161 (2018)

6. S. Timoshenko, Strength of Materials. Elementary Theory and Problems, (D. Van Nostrand Company, USA, 1940)

7. AutoCAD 2013 User's Guide (2012)

8. J. R. Taylor, An Introduction to Error Analysis - The Study of Uncertainties in Physical Measurements, (Oxford University Press, Oxford, 1982)

9. S. Timoshenko, J. N. Goodier, Theory of Elasticity (McGraw-Hill Book Company, USA, 1951)

10. ASTM D790-17, Standard Test Methods for Flexural Properties of Unreinforced and Reinforced Plastics and Electrical Insulating Materials, (ASTM International, West Conshohocken, PA, 2017)

11. Abaqus/CAE V6.14 User's Manual 